\title{
Non-Mendelian segregation and variable penetrance of colour genes in the polymorphic butterfly Danaus chrysippus (L.)
}

\author{
DAVID A. S. SMITH* \\ Natural History Museum, Eton College, Windsor, Berkshire SL4 6EW, U.K.
}

\begin{abstract}
Non-Mendelian segregation involving three colour gene loci in the butterfly Danaus chrysippus is reported. In each of the four affected broods, two of the four phenotypes expected in the progeny were absent in both sexes. Operation of a system of balanced recessive lethals is ruled out by the low egg-adult mortality recorded. All gametes were produced in expected ratios and were viable. The results are interpreted to be consistent with an inherited prezygotic incompatibility mechanism which operates at the time of fertilization. Variable penetrance of the recessive $a$ and $c$ alleles in heterozygotes is significantly influenced, in the former case by sex, and in the latter by epistatic interactions with colour genes at the $A$ and $B$ loci. The combination of non-Mendelian segregation, variable incomplete dominance and epistatic interactions with other colour genes and sex supports the hypothesis, hitherto based largely on biogeographical evidence, that the polymorphic D. chrysippus population at Dar es Salaam, Tanzania may have a hybrid origin.
\end{abstract}

Keywords: colour genes, Danaus chrysippus, epistasis, non-Mendelian segregation, penetrance, prezygotic isolation.

\section{Introduction}

Danaus chrysippus is a widespread and abundant butterfly which is distributed throughout the Old World tropics in open habitats. In Uganda, Kenya, Tanzania and neighbouring countries, but not elsewhere, an extensive range of polymorphic forms is sympatric and they interbreed freely (Owen \& Chanter, 1968; Smith, 1975a, 1980; Gordon, 1984). Unusual sex ratios have been described (Owen \& Chanter, 1968; Smith, 1975b; Gordon, 1984), both in the field and within broods; less commonly, non-Mendelian segregations for colour genes have been reported, some of which are associated with all-female broods (Smith, 1976; Gordon, 1984) and others not (Owen \& Chanter, 1968; Gordon, 1984). Moreover, there are several reports of morph ratios in the field which differ between the sexes (Smith, 1980; Smith et al., 1993, 1997). Here, I describe a type of non-Mendelian segregation not hitherto reported in D. chrysippus or, to my knowledge, in any other butterfly, together with evidence for variable penetrance of two recessive alleles contingent

*E-mail: dass@etonsci1.demon.co.uk upon, in one case sex, and in the other, epistatic interaction with two other colour gene loci. The basic colour genetics of $D$. chrysippus is now fairly well known (Clarke et al., 1973; Smith, 1975a, 1980) (Fig. 1, footnotes).

\section{Methods}

The founder pair for this study was taken in copula in the field at Dar es Salaam, Tanzania. Eggs were obtained in a sleeve on a branch of the foodplant Calotropis gigantea. All the females used are direct descendants of the founder female but wild males were sometimes introduced to obtain required matings. Pairing took place in an outdoor insectary from which mated females were removed and placed in sleeves. All broods were reared in separate cages and fed on $C$. gigantea.

\section{Results}

Non-Mendelian segregation (broods 82-85)

The broods used in this study are shown in Table 1. The founder brood 82 (Table 2) shows some unusual 
features which stimulated the remainder of the breeding programme. Segregation is 16:11 (1:1) for orange $(b b)$ : brown $(B b)$ (omitted from Table 2 for reasons of clarity), 20:7 (3:1) for dorippus $(A-C-)$ : albinus $(a a C-)$ and 10:17 for sex. The most obvious anomaly is the absence of $c c$ forewing phenotypes (chrysippus or alcippus) from the progeny; because both parents are visibly $C c$ (transiens), a 3:1 segregation, including $1 / 4 \times 27=6.75 c c$, is expected. Moreover, the eight $C c$ heterozygotes with penetrant $c$
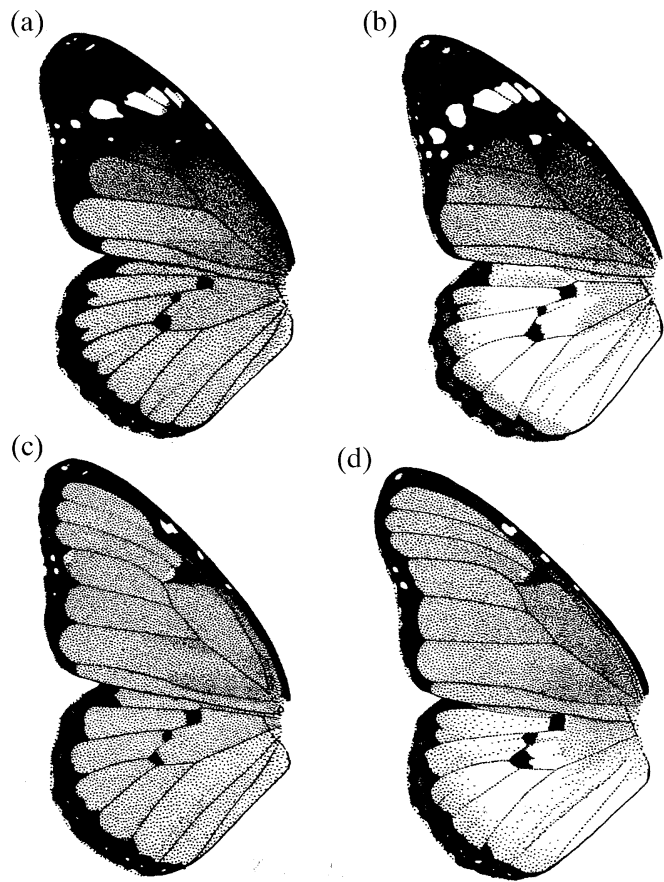

Fig. 1 The four major phenotypes of Danaus chrysippus in Tanzania: (a) chrysippus, (b) alcippus, (c) dorippus, (d) albinus. The stippled areas are either tawny orange or nutbrown; the black and white areas are as shown. Hindwing colour and pattern are controlled by the $A$ locus: (a) and (c) have the genotype $A A$, (b) and (d) are $a a ; A a$ heterozygotes are variable, being either indistinguishable from $A A$ or showing varied amounts of white (weak alcippus and albinus), especially lining the veins, but always less than in $a a$. Ground colour is controlled by the $B$ locus with two alleles, brown $(B)$ being variably dominant over orange $(b) ; B b$ heterozygotes are either brown or, more usually, show a variable extent of brown on the costal and basal areas of the forewing and the basal area of the hindwing, the remaining areas being orange. The pattern of the forewing apex is governed by the $C$ locus; (c) is $C C$ whereas (a) and (b) are $c c$; (d) has a transiens $(C c)$ forewing. The $B$ and $C$ loci are closely linked with a cross-over value of $1.9 \%$ in males only (Smith, 1975a) whereas the $A$ chromosome segregates independently; none of the colour genes is sex-linked (Clarke et al., 1973; Smith, 1975a). (transiens) are distributed nonrandomly with respect to the $A$ locus, as seven of them have the visually determinable genotypes $a a \underline{B c} / b C$ or $a a b C / b c$, whereas the $a a \underline{b C} / b C$ and $a \bar{a} \underline{B c} / b c$ genotypes are both missing. Assuming random assortment for the $A$ and $C$ loci, $\mathrm{H}_{0}$ for a 9:3:4 segregation (with the $A-c c$ and aacc classes amalgamated) is rejected $\left(\chi_{2}^{2}=9.02 ; 0.02>P>0.01\right)$. Analysed in four classes without pooling, the combined segregation for the $A$ and $C$ loci has an exact probability (two-tailed) of $1.8 \times 10^{-5}$. Association of the $A$ and $b C$ chromosomes $(n=12)$ and the $a$ and $b c$ chromosomes $(n=4)$, combined with the absence of the alternative arrangements, $a$ with $b C$ and $A$ with $b c$, has a highly significant exact probability (two-tailed) of $1.1 \times 10^{-5}$.

By deduction, the array of gamete pairings found in brood 82 (Table 3 ) suggests that half of those predicted, assuming random assortment, are absent (four cells are in doubt because penetrance of the $a$ and $c$ alleles is impossible to estimate), whereas all observed pairings exceed expectation. And yet, it is clear that all gametes, with the possible exception of $A / b c$ in males, are produced and functional.

Three $F_{2}$ broods (Table 4) were bred from the brood 82 progeny to generate better data for the interpretation of the non-Mendelian segregations observed and, as all selected parents were $a a$, to reduce genetic noise. Parents were selected for their visually identifiable $B$ - and $C$-locus genotypes. Furthermore, brood size was maximized and careful egg-adult mortality records kept. Not only were all the female parents sibs, but the same male sired two broods.

The segregation expected with independent assortment is 1:1:1:1 for $B c / b C, b C / b C, b C / b c$ and $\underline{B c} / b c$ : however, the large progenies probably comprise only two of the expected four genotypes. Yet it is clear in all these broods that both parents contribute both their $B C$ chromosomes equally to offspring of both sexes. How can I be sure that all the orange albinus should be scored as $a a b C / b c$ rather than $a a b C / b C$ ? Two facts support the interpretation that the latter genotype is missing. First, the penetrance of $c$ in these broods is slightly above average and homogeneous, $47 \%$ in $b c / b c$ and $81.9 \%$ in $B c / b C$, compared to $45 \%(n=\overline{129})$ and $74.4 \%$ $(n=173)$, respectively, in known backcross progenies from Tanzania (Smith, 1980); secondly, all three brood segregations fit a 1:1 expectation; there is no surplus of orange $(b b)$ individuals which would be expected if both $\underline{b c / b c}$ and $b C / b C$ genotypes were recovered. A parsimonious interpretation is that the $\underline{b C} \underline{b C}$ genotype is missing, as is the easily recog- 
Table 1 Eight broods of Danaus chrysippus reared at Dar es Salaam, Tanzania

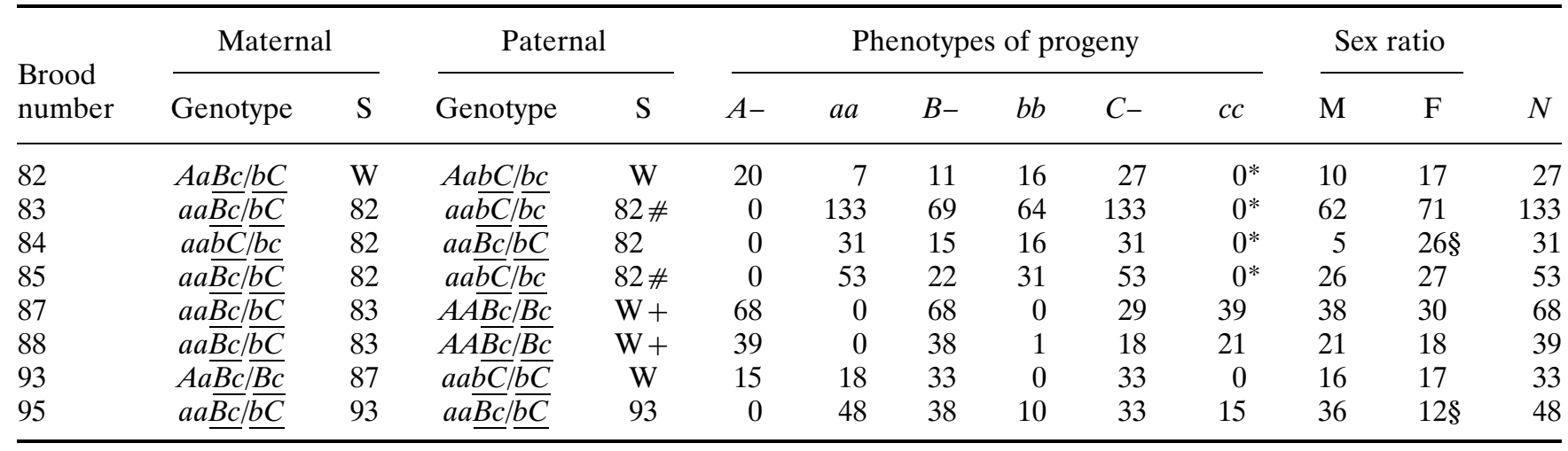

$\mathrm{S}$, source; W, wild; M, male; F, female.

*Phenotype ratio departs significantly from expectation on the assumption that alleles are inherited randomly. $\#,+$ indicate the same male parent.

$\S$ Sex ratio $\neq 1: 1(P<0.001)$.

nized $\underline{B c} / b c$ genotype. Note that both these genotypes are also absent from the parental brood 82 .

\section{Penetrance of the $\mathrm{c}$ allele in Cc heterozygotes}

Penetrance of the $a$ and $c$ alleles clearly varies with genetic background in broods 82-85. Broods 87-95 were reared to provide larger samples for estimating penetrance against a wider variety of genetic backgrounds. The results for the $C$ locus (Table 5) show that penetrance of $c$ in $C c$ genotypes is higher in a $B b(72.3 \%)$ than a $b b(44.9 \%)$ background and in $a a$ $(67.6 \%)$ compared to $A$ - $(49.0 \%)$ genotypes. Because the $\chi^{2}$-value for interaction is not significant, the two effects are probably additive, the

Table 2 Segregation for the $A$ and $C$ loci in brood 82 of Danaus chrysippus (expected numbers in parentheses): the parental genotypes are $A a \underline{B c} / \underline{b C}$ (female) and $A a \underline{b C} / \underline{b c}$ (male)

\begin{tabular}{|c|c|c|c|c|c|}
\hline \multirow{2}{*}{$\begin{array}{l}\text { C-locus } \\
\text { genotypes }\end{array}$} & \multicolumn{4}{|c|}{$A$-locus genotypes } & \multirow[b]{2}{*}{$N$} \\
\hline & $A-$ & $A a$ & $A-+A a$ & $a a$ & \\
\hline$C_{-}$ & 16 & 3 & 19 & 0 & 19 \\
\hline$C c$ & 0 & 1 & 1 & 7 & 8 \\
\hline$C-+C c$ & 16 & 4 & $\begin{array}{c}20 \\
(15.19)\end{array}$ & $\begin{array}{c}7 \\
(5.06)\end{array}$ & $\begin{array}{c}27 \\
(20.25)\end{array}$ \\
\hline$c c$ & 0 & 0 & $\begin{array}{c}0 \\
(5.06)\end{array}$ & $\begin{array}{c}0 \\
(1.69)\end{array}$ & $\begin{array}{c}0 \\
(6.75)\end{array}$ \\
\hline$N$ & 16 & 4 & 20 & 7 & 27 \\
\hline
\end{tabular}

$\chi_{2}^{2}$ for 9:3:4 with classes $A-C-, a a C-$ and $--c c=9.02$, $0.02>P>0.01$. Segregation at the $B$ locus is $11 B b$ (brown): $16 b b$ (orange), a good fit to 1:1. $a a B b C c$ genotype showing penetrance of $83.3 \%$, compared to $0 \%$ for $A-b b C c$ (this sample is small $(n=12)$ and the estimate atypically low). The highly significant interaction between the $A$ - and $B$-locus segregations is caused by the non-Mendelian effects described above for broods $82-85$. Penetrance is probably not generally affected by $\operatorname{sex}\left(\chi_{1}^{2}=3.44\right.$, $0.1>P>0.05)$ although the influence of sex is significantly heterogeneous $\left(\chi_{3}^{2}=10.99,0.02>P>0.01\right)$ and requires further investigation.

\section{Penetrance of the a allele in Aa heterozygotes}

In contrast to the $C$ locus, penetrance of $a$ in $A a$ heterozygotes (Table 6) is strongly influenced by sex, as it is significantly higher $(62.5 \%)$ in males than females $(25.5 \%)$. It is not, however, affected by $C$-locus genotype; a possible $B$-locus effect cannot be tested with these data as broods $87-88$ are entirely brown.

\section{Discussion}

\section{Non-Mendelian segregation}

The segregations in broods $82-85$, and especially the last three, suggest at first glance the operation of a balanced recessive lethal system. This interpretation is, however, effectively ruled out by the mortality data for broods 83-85 (Table 4) which show that the mean egg-adult mortality of $26.4 \%$ is well below the minimum of $50 \%$ expected if two classes from a 1:1:1:1 segregation were to suffer total mortality. Brood mortality is, moreover, well below the

(c) The Genetical Society of Great Britain, Heredity, 80, 474-480. 
Table 3 Observed numbers of gamete pairings and their deduced compatibilities in brood 82 of Danaus chrysippus

\begin{tabular}{lccccc}
\hline \multirow{2}{*}{$\begin{array}{l}\text { Female } \\
\text { gametes }\end{array}$} & $A / b C$ & $A / b c$ & $a / b C$ & $a / b c$ & $\begin{array}{c}N \text { observed } \\
\text { in progeny }\end{array}$ \\
\cline { 2 - 5 }$A / B c$ & 6 & 0 & $0-2 \#$ & 0 & $6-8$ \\
$A / b C$ & $+{ }^{1}$ & - & $+^{2}$ & - & $10-12$ \\
$a / B c$ & 10 & 0 & $0-2 \S$ & 0 & $3-5$ \\
$a / b C$ & + & - & + & - & 0 \\
& $0-2 \#$ & 0 & 3 & 0 & $4-6$ \\
$N$ observed in progeny & $++^{2}$ & - & $+{ }^{* 3}$ & $-{ }^{*}$ & 4 \\
\hline
\end{tabular}

+ , compatible; - , incompatible pairings. Where a range of numbers is shown (\# and $\S$ ), the gamete pairing is in doubt because the genotype derived from it can also be obtained from the reciprocal pairing; in the latter case ( $\S)$ the $A a b C / b C$ genotype may be missing as the two orange semialbinus individuals could be $A a b C / b c$ with impenetrant $c$. ${ }^{1}$ Zero penetrance by $c$ allele; ${ }^{2}$ some penetrance by $c$ allele; ${ }^{3}$ high penetrance by $c$ allele. ${ }^{*}$ Results confirmed in broods $83-85$

average of $39.8 \% \quad(n=52$ broods measured $)$ for bisexual broods reared by me in Tanzania and is homogeneous across the three broods. Preoviposition mortality or reabsorption of eggs probably never occurs in butterflies because eggs are fertilized singly, immediately before laying, as they pass the opening from the bursa copulatrix. Usually females carry only one fertilized egg at a time.

In broods 83-85 (Table 4), all gametes are viable and apparently produced by both sexes in equal numbers. As both types of sperm are equally recovered in the progeny, sperm competition is ruled out. Compatible pairings are $B c$ with $b C$ and $b C$ with $b c$ and incompatible pairings $b C$ with $b C$ and $B c$ with $b c$. As these four pairings behave, in terms of compatibility, identically among the three $\mathrm{F}_{2}$ broods and the parental brood 82 , the mechanism must be inherited. Moreover, because broods 83 and 85 , on the one hand, and 84 on the other, are reciprocal crosses, compatibility must be irrespective of

Table $4 \mathrm{~F}_{2}$ broods of Danaus chrysippus from which two expected phenotypic classes are missing in both sexes

\begin{tabular}{|c|c|c|c|c|c|c|c|c|c|c|c|}
\hline \multirow{3}{*}{$\begin{array}{l}\text { Brood } \\
\text { number }\end{array}$} & \multirow{2}{*}{\multicolumn{2}{|c|}{$\begin{array}{l}\text { Parental } \\
\text { genotypes }\end{array}$}} & \multicolumn{8}{|c|}{ Genotypes of progeny } & \multirow[b]{3}{*}{$N$} \\
\hline & & & \multicolumn{4}{|c|}{ Males } & \multicolumn{4}{|c|}{ Females } & \\
\hline & Female & Male & $\underline{B c} / \underline{b C}$ & $\underline{b C} / \underline{b C}$ & $\underline{b C} / \underline{b c}$ & $\underline{B c} / \underline{b c}$ & $\underline{B c} / \underline{b C}$ & $\underline{b C} / \underline{b C}$ & $\underline{b C} / \underline{b c}$ & $\underline{B c} / \underline{b c}$ & \\
\hline 83 & $B c / b C$ & $b C / b c$ & 35 & 0 & 27 & 0 & 34 & 0 & 37 & 0 & 133 \\
\hline 84 & $\overline{b c} / \overline{b c}$ & $\overline{B c} / \overline{b C}$ & 2 & 0 & 3 & 0 & 13 & 0 & 13 & 0 & 31 \\
\hline 85 & $\overline{B c} / \overline{b C}$ & $\overline{b c} \overline{/ b c}$ & 12 & 0 & 10 & 0 & 14 & 0 & 17 & 0 & 53 \\
\hline Totals & & & 49 & 0 & 40 & 0 & 61 & 0 & 67 & 0 & 217 \\
\hline
\end{tabular}

All parents are genotype $a a$ sibs from brood 82 . The same male sired broods 83 and 85 . $\mathrm{H}_{0}$ is for a segregation of $1: 1: 1: 1$ but all broods fit a 1:1 ratio for genotypes with no heterogeneity $\left(\chi_{3}^{2}=2.0,0.7>P>0.5\right)$. Brood 84 is biased to females $\left(\chi_{1}^{2}=14.2, P<0.001\right)$ and the overall SR is also female-biased $\left(\chi_{1}^{2}=7.0, P<0.01\right)$. However, without 84 , SR in the remaining broods is normal $\left(\chi_{1}^{2}=1.7,0.2>P>0.1\right)$. Egg-adult mortality $(\%)$ in the three broods is, respectively, 26.9 , 27.9 and 24.3 . 
Table 5 Penetrance of the $c$ allele in $C c$ genotypes of Danaus chrysippus against different genetic backgrounds (broods 82-95) (expected numbers in parentheses)

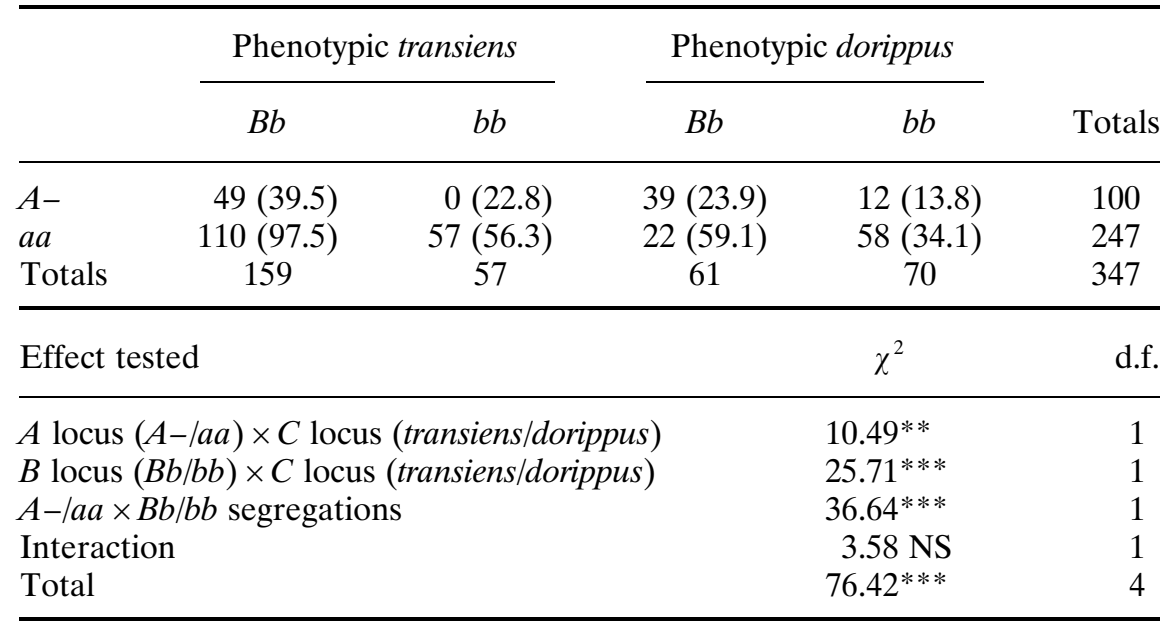

Analysis of $\chi^{2}$ follows the method of Lewis (1962). ${ }^{* *} 0.01>P>0.001$,

$* * * P<0.001$.

whether the haploid genomes involved are carried by sperm or eggs. These results suggest the operation of a prezygotic isolating mechanism which operates at the point of fertilization.

It may be relevant that the parents of brood 82 are heterozygous for three genes with alleles which are at fixation in the allopatric subspecies chrysippus $(A A b b c c)$ (North Africa and Asia), liboria $(A A B B c c)$ (southern Africa), alcippus (aabbcc) (West Africa) and dorippus (AAbbCC) (north-east Africa), all of which overlap and interbreed in Tanzania. Recombination through independent $A / B C$ assortment in both sexes and $B / C$ cross-over in males has resulted in many phenotypes (transiens $(---C c)$, brown dorippus $(A-B-C-)$ and albinus $(a a--C-)$ which are confined to the postulated hybrid zone. It may be

Table 6 Penetrance of the $a$ allele in Aa genotypes of Danaus chrysippus against different genetic backgrounds (broods 87-88) (expected numbers in parentheses)

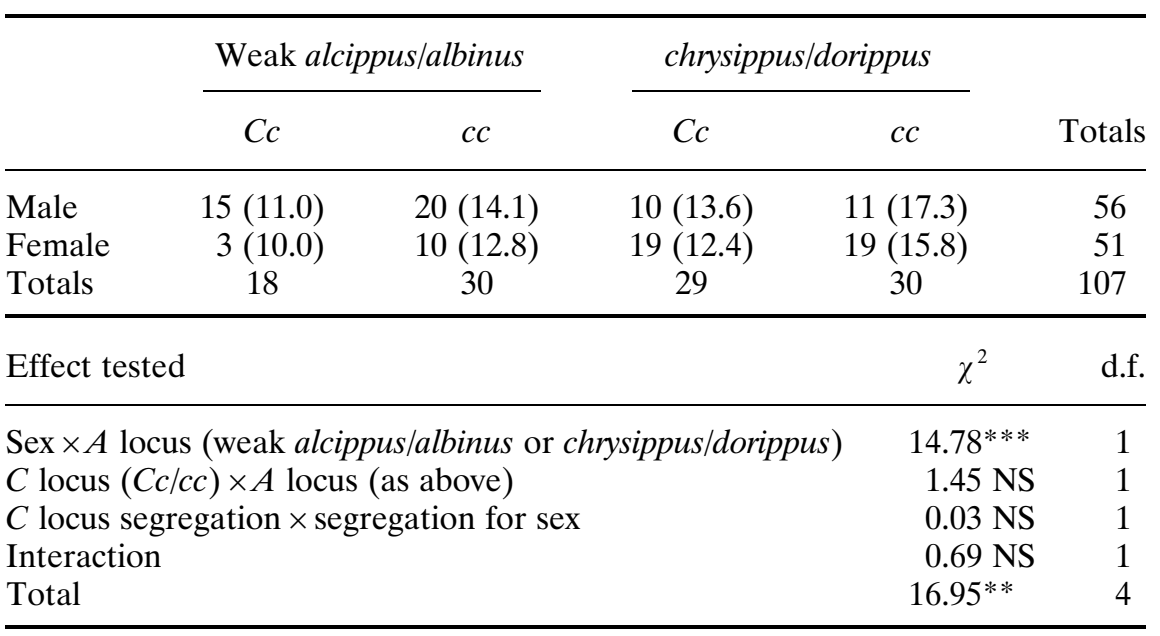

Analysis of $\chi^{2}$ follows the method of Lewis (1962). ${ }^{* *} 0.01>P>0.001$, $* * * P<0.001$. 
that prezygotic isolation, together with disturbed sex ratios, indicates incipient speciation involving two or more of these subspecies.

\section{Variable penetrance of the $a$ and $c$ alleles}

Penetrance of the $a$ allele is apparently unaffected by genotype at the $C$ locus and a possible effect from the $B$ locus remains to be investigated. The partial sex-limitation of penetrance is possibly a stage in the evolution of full sex-limited inheritance which is rather common in butterflies (though not in Batesian models such as D. chrysippus), e.g. Papilio dardanus (Clarke \& Sheppard, 1963) and P. memnon (Clarke et al., 1968), Hypolimnas misippus (Smith \& Gordon, 1987; Gordon \& Smith, 1989) and $H$. bolina (Clarke \& Sheppard, 1975), Colias and Catopsilia species, although in all these cases it is the male in which gene penetrance is suppressed. However, in Pseudacraea eurytus (Carpenter, 1949; Owen \& Chanter, 1972) sex-limited phenotypes occur in both sexes. Expressivity of $a$ in the $A a$ genotype is very variable; at the extremes, individuals with, on the one hand, a few white scales lining the hindwing veins and, on the other, a white patch scarcely smaller than found in $a a$ individuals, suggests that evolution of dominance has not occurred. It is my impression that, not only penetrance but also expressivity (which has not been measured), is higher in males. Owen \& Chanter (1968), working in Uganda, found that the frequency of weak alcippus $(A a)$ was significantly lower in the field than in a sample reared from wild-collected larvae. They suggested that selection for distinctiveness between the polymorphic forms, which improves mimetic resemblance to $H$. misippus and Acraea encedon (now known to include $A$. encedana (Owen et al., 1994)), might be responsible. If this is the case, selection for improved mimicry is stronger in the female than the male.

Interaction of the $C$ and $c$ alleles in $C$-locus heterozygotes differs from the $A$-locus interaction in that the phenotype of the transiens $(C c)$ form (with penetrant $c$ ) is much closer to dorippus than to chrysippus, indeed so much so that it is unlikely that any predator would discriminate between transiens and dorippus. In this case dominance may have evolved, an hypothesis which is testable by crossing distantly allopatric races. On the other hand, the near dominance of the $C$ allele may be a simple consequence of the biochemistry of gene action.

The penetrance data at both $A$ and $C$ loci, showing as they do multiple epistatic interactions with sex and other loci, which in turn have variable penetrance, serve to emphasize the practical impossibility on present knowledge of measuring allele frequencies at any of the $A, B$ or $C$ loci directly from field samples. Moreover, the occurrence of non-Mendelian segregations for phenotype, not only of the type described here, but also associated with all-female broods (Smith, 1975b, 1976; Gordon, 1984) and bisexual broods (Gordon, 1984) strongly suggests that intergeneration changes of colour gene frequencies are at present hard to predict. The highly complex set of interactions in the polymorphic population at Dar es Salaam has probably arisen as a result of the recent admixture of several well-differentiated subspecies to form an extensive hybrid zone.

\section{Acknow ledgements}

I am grateful to the University of Dar es Salaam for providing the facilities for carrying out this work. Dr Derek Whiteley drew Fig. 1.

\section{References}

CARPenter, G. D. H. 1949. Pseudacraea eurytus (L.) (Lep. Nymphalidae): a study of a polymorphic mimic in various degrees of speciation. Trans. R. Ent. Soc. Lond., 100, 71-133.

ClARKE, C. A. AND SHEPPARD, P. M. 1963. Interactions between major genes and polygenes in the determination of mimetic patterns of Papilio dardanus. Evolution, 17, 404-413.

ClARKE, C. A. AND SHEPPARD, P. M. 1975. The genetics of the mimetic butterfly Hypolimnas bolina (L.). Phil. Trans. R. Soc., 272, 229-265.

ClARKE, C. A., SHEPPARD, P. M. AND THORNTON, I. W. B. 1968. The genetics of the mimetic butterfly Papilio memnon L. Phil. Trans. R. Soc., 254, 37-89.

Clarke, C. A., SHePpard, P. M. AND SMith, A. G. 1973. The genetics of fore and hindwing colour in crosses between Danaus chrysippus from Australia and from Sierra Leone (Danaidae). J. Lepidopt. Soc., 27, 73-77.

GORDON, I. J. 1984. Polymorphism of the tropical butterfly Danaus chrysippus L. in Africa. Heredity, 53, 583-593.

GORDON, I. J. AND SMITH, D. A. S. 1989. Genetics of the mimetic African butterfly Hypolimnas misippus: hindwing polymorphism. Heredity, 63, 409-425.

LEWIS, B. N. 1962. On the analysis of interaction in multidimensional contingency tables. J. R. Statist. Soc., 125, 88-117.

OWEN, D. F. AND CHANTER, D. O. 1968. Population biology of tropical African butterflies. 2. Sex ratio and polymorphism in Danaus chrysippus L. Rev. Zool. Bot. Afr., 78, 81-97.

OWEN, D. F. AND CHANTER, D. O. 1972. Polymorphic mimicry in a population of the African butterfly, Pseu- 
dacraea eurytus (L.) (Lep. Nymphalidae). Ent. scand., 3, 258-266.

OWEN, D. F., SMITH, D. A. S., GORDON, I. J. AND OWINY, A. м. 1994. Polymorphic Müllerian mimicry in a group of African butterflies: a re-assessment of the relationship between Danaus chrysippus, Acraea encedon and Acraea encedana (Lepidoptera: Nymphalidae). J. Zool. Lond., 232, 93-108.

SMITH, D. A. s. 1975a. Genetics of some polymorphic forms of the African butterfly Danaus chrysippus L. (Lepidoptera: Danaidae). Ent. scand., 6, 134-144.

SMITH, D. A. s. 1975 b. All-female broods in Danaus chrysippus $\mathrm{L}$. and their ecological significance. Heredity, 34, 363-371.

SMITH, D. A. s. 1976. Evidence for autosomal meiotic drive in the butterfly Danaus chrysippus. Heredity, 36, 139-142.
SмiтH, D. A. s. 1980. Heterosis, epistasis and linkage disequilibrium in a wild population of the polymorphic butterfly Danaus chrysippus. Zool. J. Linn. Soc., 69, 87-109.

SMITH, D. A. S. AND GORDON, I. J. 1987. The genetics of the polymorphic tropical butterfly Hypolimnas misippus: the classification of phenotypes and the inheritance of forms misippus and inaria. Heredity, 59, 467-475.

SMITH, D. A. S., OWEN, D. F., GORDON, I. J. AND OWINY, A. M. 1993. Polymorphism and evolution in the butterfly Danaus chrysippus (L.) (Lepidoptera: Danainae). Heredity, 71, 242-251.

SMITH, D. A. S., OWEN, D. F., GORDON, I. J. AND LOWIS, N. K. 1997. The butterfly Danaus chrysippus (L.) in East Africa: polymorphism and morph-ratio clines within a complex, extensive and dynamic hybrid zone. Zool. J. Linn. Soc., 120, 51-78. 